\title{
Research on Constructing the System of Governing the Environment of the Yangtze River Delta Region by Law
}

\author{
Xiang-Kui GENG \\ Zhejiang ocean university school of economics and \\ Management Zhejiang zhoushan 316022 \\ E-mail: gxk66@126.com
}

\begin{abstract}
The Yangtze River Delta region is one of the best and most competitive areas in the eastern coastal areas of China, which plays a very important role in stimulating national economic growth. However, with the Yangtze River Delta region's rising GDP, environmental degradation has become quite prominent. Although the government at all levels of the region are very concerned about the pollution, the effect is still far from satisfaction. On the basis of discussing the basic situation of the regional environment and the main pollution in the Yangtze River Delta region, the author elaborates on the main problems of governing the regional environment in the Yangtze River Delta region according to law. Based on this, it puts forward the strategy of constructing the environmental system mechanism of governing Yangtze River Delta by law.
\end{abstract}

Keywords-Construction; rule by law; Yangtze River Delta regional environment; institutional mechanisms

The Yangtze River Delta is one of the best and most competitive areas in the eastern coastal areas of China. It is well-developed in industry, urbanization, economy, science and education. It plays an important role in stimulating national economic growth. The total GDP of the region in 2013 is close to 10 trillion Yuan (977.6 billion), accounting for $17.2 \%$ of the country. In 2013, the GDP of the Yangtze River Delta region is nearly 10 trillion Yuan, accounting for $17.2 \%$ of the national GDP. In 2014, the GDP of 16 cities reached

10.60 trillion Yuan, above-scale industrial output value exceeded 19 trillion Yuan, the fixed asset

\author{
Zeng-Hang LI \\ Zhejiang ocean university school of economics and \\ management Zhejiang zhoushan 316022 \\ E-mail: gxk66@126.com
}

investment completed a breakthrough of 5 trillion Yuan. The total retail sales of social consumer goods valued 3.95 trillion Yuan and total imports and exports 1.29 trillion US dollars. In 2015, the GDP of 16 cities reached 11.3 trillion Yuan, an increase of $8.2 \%$, with the growth rate down 0.3 percentage points over the previous year, higher than the national average of 1.3. However, with the rapid economic development in the Yangtze River Delta region and the increasing floating population, the ecological environment deteriorated sharply, it is imperative to govern this region according to the law.

\section{THE BASIC SituATION OF THE YANGTZE RIVER}

\section{DELTA REGIONAL ENVIRONMENT AND THE MAJOR}

\section{POLLUTION}

In recent years, the Yangtze River Delta region's GDP is rising, but the environment is continuing to deteriorate, the problem is ever more prominent. Although the government at all levels of the region are very concerned about the pollution problem, they have increased the efforts of remediation, the environmental quality is still far from satisfaction. Overall, the Yangtze River Delta environmental problems highlighted in two aspects.

Firstly, regional water pollution is becoming increasingly serious, the cross-site water pollution incidents occur frequently. According to statistics, the Yangtze River Delta core area of the Taihu Lake Basin annual water quality or class III river length of only $16.6 \%$ (the total river length is $5778.3 \mathrm{~km}$ ). There are excessive 
ammonia, phosphorus, nitrogen in the water, and the lake is eutrophicated. Entering into the 21st century, water pollution became more serious, there have been a cyclical cyanobacteria outbreak. In 2005, at the junction of Jiangsu and Zhejiang province, Lanxi pond junction waters (Tongluo town in Suzhou Wujiang, Jiangsu to Xincheng town in iaxing Xiuzhou, Zhejiang) and the north tributary of Xincheng Pond River became black and smelly due to pollution. Xin Cheng town water plant was forced to close down, resulting in more than 30,000 residents in Jialing's drinking water supply disruption. In May and June of 2007, Taihu blue algae pollution incident led to water pollution in Wuxi city, bottled water in supermarkets and shops was sold out. In2012, Korean ship phenol leakage polluted the Yangtze River in Jiangsu Zhenjiang, triggering Zhenjiang snapping drinking water storm, affecting the downstream city residents were all influenced.

In March of 2013, Shanghai Songjiang "dead pig incident" (the accumulated salvage vessels reached 233 by March 12, finishing a total of 5916 pigs), seriously damaged the international image of Shanghai. Although the central and local governments paid high attention to this incident, there has been little effect of regional water quality control. In 2001, the State Environmental Protection Administration and the Ministry of Water Resources coordinated Jiangsu and Zhejiang to reach consensus on "the coordinated opinion of water pollution in Jiangsu and Zhejiang Jiaxing", and put forward the emergency measures to solve the pollution dispute. But the result is still worrying.

Secondly, regional air pollution is serious and presents a trend of regional diffusion. Such major cities as Nanjing, Xuzhou and other cities in the Yangtze River Delta region only have less than $50 \%$ days in a year meeting the air quality standards. Zhou Shan is the only city with more days meeting the air quality standards. Shanghai suffered from much more serious pollution, with only $65.2 \%$ days meeting the air quality standard in the first half of the year. The situation got worse in the second half of the year. The main source of air pollution is the industrial waste and automobile exhaust. Among them, PM2.5 particles are mainly from the motor vehicle exhaust, which exerted a direct impact on urban visibility.
It is also the root cause of the haze in Yangtze River Delta cities in recent years. Take Shanghai as an example, in 2000 the city's motor vehicles amounted to 1.048 million. By the end of 2012, registered ownership of motor vehicles has reached 2.623 million, 1.5 times more than ten years ago. Relevant studies found out that motor vehicle emissions accounted for more than $50 \%$ of urban air pollutant emissions. Because of regional geographical conditions and meteorological conditions, the Yangtze River Delta region air pollution transmission across the city is more obvious. A large number of pollutants crossborder transmission not only increased the recipient city's pollution, but also caused the secondary pollution formation and increased the potential conditions. Therefore, the traditional method for controlling a single city's air pollution is no longer applicable. We need to have the regional and even a wider range of perspective to conduct air pollution control through the regional defense.

\section{The MAJOR PROBLEMS OF GOVERNING REGIONAL} ENVIRONMENT IN THE YANGTZE RIVER DELTA REGION

\section{ACCORDING TO THE LAW}

China's environmental legislation started a relatively short time ago and there are many loopholes in the laws and regulations. It is difficult to form a unified whole and the environmental protection laws become furnishings. There are many reasons. Different legal person from different classes have their own interests and appeals, and there is no legal norms of regional cooperation. And the local governments on the environment. The local environmental intervention on the law enforcement of protecting the environment is also another cause.

Firstly, the environmental legal system design is imperfect. Problems in real life depends on laws and regulations. However, it is difficult to find detailed legal provisions because there is no relevant code of conduct and legal consequences even if there is a relevant provision in the legal system. A. Institutional design lacks overall coordination. The current environmental legislation vertical and horizontal coordination is not in place. There are no supporting laws and regulations and specific implementation methods, low feasibility is another problem even if there are. But the system design ideas are unknown, and there is no complete coordination 
and no measures to match with the initiative. For example, Article XV in the "Air Pollution Control Law" provides: "local government within the control range of air pollutants may issue emissions and permits to enterprises according to the State Council's conditions and procedures". But as a supporting regulation, the" Sewage Permit Management Regulations" only issued a draft in 2008. It became a law hanging in the air because of the lack of specific laws and regulations. B. Part of the legal system lacks the consequences of responsibility. We still take the sewage permit system as an example, it is a lawful application from the legislative point of view. But there is no specific measures of punishment for behaviors such as non-application, emission without a permit. The corresponding legal consequences of prohibited or restrictive legal norms are also absent. C. Local legislation failed to match the upper law. There are much absence of local legislation, leading to the relevant system failed to be implemented to the specific level, making the existing environmental legal system is useless and useless. Local legislation should strictly define rights and obligations of government management, local organization and individuals for the purpose of solving actual problems according to local characteristics, in order to make the upper law more operational and easier to implement. The "Environmental Protection Law", with its abstraction and principled characteristics, need to be carried out specific provisions such as the amount of punishment, the implementation details and so on according to local real situation. However, some local legislation advocates law-based legislation and onesided pursuit of legal system integrity, ignoring the local reality and needs. So that legislation becomes a repetitive legislation, a large number of provisions are a plagiarism of the upper law.

Secondly, the current environmental administrative penalties lack of strength. As an effective means of preventing and punishing the relevant environmental violations, the environmental administrative punishment is an important manifestation of the rule of law administration according to law and government-led environmental management. To punish environmental pollution and the economic sanctions are to make people dare not to violate the law, in order to achieve the goal of protecting environmental resources. However, the existing environmental law on the legal consequences of illegal provisions is difficult to produce deterrent. China's environmental legislation for illegal offenders usually adopts a one-time fine (economic penalties), and limits the maximum amount of fines. This kind of punishment mode does not take into account the environmental pollution time and illegal income. Therefore, it easily leads to administrative punishment with no effective deterrent, making the administrative punishment facing "useless penalty" dilemma. Enterprises as the market rational economic entities are easy to choose illegal business if the law-abiding costs are much higher than the illegal costs.

Thirdly, regional environmental governance cooperation lacks relevant laws and regulations. A. Regional environmental management law is absent. In recent years, the governments at all levels of the Yangtze River Delta region are troubled by long-term crossregional pollution incidents. However, the lack of regional planning and laws and regulations, imperfect regional policy and regulatory carriers resulted in sectorial conflicts and regional conflicts. There are other causes as the absence of cross-border pollution regulation and the absence of specific law enforcement. Because the legal provisions are very general, and the legislation system is not clearly designed, coupled with the local governmental "rational person" features, the consequence is to fight for profits, responsibility prevarication in the absence of legal and policy constraints. B. Regional cooperation lacks long-term mechanism and legal carrier. Yangtze River Delta local governments are also trying to explore the administrative cooperation in the management of water pollution model. Jiangsu and Zhejiang also in reached a coordinated opinion under the auspices of State Environmental Protection Administration and the Ministry of Water Resources. In 2005, Jiangsu and Zhejiang provinces have formed six mechanisms featuring a joint water quality monitoring mechanism, information management mechanism, water environment joint law enforcement mechanism, infrastructure sharing mechanism, regional ecological compensation mechanism and emission trading mechanism and other cross-administrative areas 
of water pollution prevention and control mechanism. But because of the lack of the corresponding regional law, the degree of cooperation still has no legal carrier and protection. The main forms of administrative cooperation are the joint meeting of mayors of the Yangtze River Delta, the joint meeting of the Yangtze River Delta cooperation and development and the government cooperation agreements signed at all levels of government. But it does not involve the implementation of specific cooperation contents and enforcement procedures. The administrative cooperation agreement is limited to a letter of intent, or even a waste paper, because it is difficult to implement. In addition, many administrative cooperation is to meet the needs of large-scale activities, it is mostly "sport-like" temporary measures, which is difficult to form a long-term institutionalization. C. Regional environmental management agency is absent in the regional cooperation. In the existing system design, the Taihu Lake Basin Authority has the responsibility of water pollution prevention and control, but the authority is very limited, which determines that there is no corresponding guarantee to achieve its function. Coupled with the fact that the division of authority with the local authorities is not clear, it is difficult to assume the responsibility of regional environmental management agencies. We can only "take the local administrative region management as the center", which barely have a say in such important matters as penalties, environmental standards and pollution control planning. At the same time, there are contradictions and conflicts between the legal provisions. The "Water Law" provides "combine the watershed management with regional management", while the "Water Pollution Control Law" Article 28 provides for local government to coordinate and manage. Therefore, the water environment management is actually a combination of watershed management with regional management. But the actual leading role is the provincial (municipalities and autonomous regions) as well as the local water management agencies at all levels. The unified management mechanism of watershed management agencies does not play its function as expected. D. Lack of supporting legal institution in regional cooperation. In order to solve the environmental pollution cross the administrative region, the governments at all levels in the Yangtze River Delta region have tried various solutions. The two provinces and municipalities have also cooperated with each other to complete the "Yangtze River Delta Energy Conservation and Environmental Protection Regional Cooperation Research" report, and proposed to improve the regional energy consumption standards. It is suggested that the two provinces and governments of Jiangsu and Zhejiang provinces have reached the "Opinions on the Contamination of Water Pollution and Water Maturity between Jiangsu Suzhou and Jiaxing, Jiangsu Province" under the mediation of the State Environmental Protection Administration and the Ministry of Water Resources. Environmental law scholars also put forward: "There should be a combination of central legislation and local legislation, combination of comprehensive legislation an single legislation, combination of regional legislation with watershed legislation, combination of substantive legislation and procedural legislation in the management of laws and regulations as well as the combination of water management and water quality protection legislation in the policy and system of water environment management across administrative regions. They also pointed out that" the urgency is to develop a comprehensive framework law of cross-administrative water environment management.

Fourthly, the interference of local management system on the regional environmental law enforcement. Administrative decentralization and taxation reform highlighted that the local government has to assume more administrative functions, while fiscal revenue and budget revenue are too low. Therefore, as a rational local government, in its own conditions, it is likely to ignore the environmental law enforcement, blindly pursue economic growth in order to increase the local government's fiscal revenue. At the same time, the current official promotion system is not conducive to officials to fulfill their environmental responsibilities. A. Over-burdened responsibilities and limited financial abilities. Decentralization reform makes the pressure amplified from the central government to the local governments. The lower the administrative level is, the 
more administrative affairs it should burden. Under the vertical system, the affairs of higher legal authority often become the subordinate governments'. In reality, means such as higher-level assessment, one-vote negate make the responsibility of this level into subordinate responsibility. However, in the financial decentralization, the higher government authorities determine the budget of the lower level government. The higher the administrative level is, the more budget it will get. The county government is only a passive recipients of the tax sharing rules developed by the superiors, it basically has no adjustment capacity over its budget income is . Therefore, the lower the local government level is, the less budget they will get. On the contrary, the need to burden more administrative affairs and more responsibilities. B. Environmental law enforcement is subject to local financial investment. Local governments have to bear the expenses of political operation, economic development, social undertakings as well as public affairs management services such as pension, law and order, medical care, education and many other matters. Environmental protection is one of the many functional responsibilities. The revenue mostly goes to the central government after the tax reform, so the local governments are often stretched and a lot of responsibilities are difficult to be performed well. Therefore, concerning the distribution of fiscal expenditure, the local governments often give priority to solve the urgent problem of people's livelihood, and environmental protection is usually considered as a task which is not so urgent. Therefore, it is easy to be shelved aside or arranged for less financial resources. Although the economic situation in the Yangtze River Delta region is slightly better, environmental protection investment is increasing, the local government has become accustomed to the "pollute first and then control" development model, so they are not prepared the financial funds and psychological preparation for longterm controlling of pollution. C. Tax competition reduced the regional environmental access threshold. The Yangtze River Delta boasts rich resource and similar industrial structure. The administrative system of "substove eating" has led to the rigid local interests and the path dependence, resulting in the decentralization of the regional factors and the convergence of the industrial structure. In order to get better fiscal revenue and GDP assessment performance, the local government has long been too much emphasized on economic development. The main purpose of attracting investment is to increase the tax sources, ignoring the ecological protection. The extensive economic growth in the region prevailed for a long time. Local governments give priority to the interests of organization and members of organization, in order to obtain direct economic benefits, they even introduced some highly polluting chemical, printing and dyeing industry projects regardless of the environment. The absence of incentive system for environmental governance made the local governments have little incentive to control environmental pollution. On the contrary, they always maximize the protection of their major taxpayer out of local protectionism, and do not want to penalize their polluting behavior. D. The negative impact of performance evaluation system. Law enforcement efficiency depends both on the executive's overall quality and the ability to execute, as well as the confidence and attitudes of law enforcement. At the same time, it also depends on whether local officials can benefit from the law enforcement. Therefore, the performance evaluation indicators have a great impact on environmental rule of law. The current cadre assessment mechanism focus on economic indicators, which greatly stimulated the local government leaders to promote economic development, they always put GDP first. Because among all the indicators evaluation of the officials, economy is the most easily quantified indicator while environmental protection is difficult to quantify. Therefore it is easy to become an administrative function ignored by the local leader "rationally". At the same time, because of the pursuit for promotion, local leaders tend to be stuck in one-sided pursuit of rapid economic development. They are always emphasizing economic indicators, keen on the project launching, engage in image engineering, performance projects. So it is easy to occur duplication and industry homogenization, which not only leads to the waste of land resources but also serious environmental pollution. 


\section{COUNTERMEASURES TO BUILD}

\section{ENVIRONMENTAL MECHANISM GOVERNING THE}

YANGTZE RIVER DELTA UNDER THE LAW.

The environment of the Yangtze River Delta region continues to deteriorate and the land carrying capacity approaches its limit. In order to restrict the local government's "rational people" and avoid disadvantages soa s to reverse the Yangtze River Delta's deterioration, in the existing system framework, we must introduce social supervision and public participation mechanism. We have to improve the system from legislation, law enforcement for the purpose of preventing the government from abuse of the environment resources. We have to make environmental pollution prevention and control standardized and lea gal as well as build environmental mechanism governing the Yangtze River Delta under the law.

Firstly, we shall build a sound regional environmental legal system. A. To establish a sound and harmonized environmental legal system. a. To define system design ideas and specific legal consequences. Targeted laws and regulations and local laws and regulations should be developed so as to make the environmental protection system coordinated and harmonized and avoid the legal system being nothing due to lack of binding and deterrent forces; Local government should define its environment duty and regulate its environmental protection responsibilities in accordance with the law. You can learn from the enumeration technique used in the legislation department in the United States, that is to say, to list all the situations that might arise from environment protection and disposal methods. Legal provisions shall define such duties as management planning, systems, objectives, strengthening information notification, ecological compensation. Pollution inspection and accountability shall also be cleared to avoid local protectionism. b. To establish the concept of integrated legislation for regional environment. In the past, environmental legislation is restricted by administrative divisions. The overall environmental segmentation lacks the consideration of regional environment as a whole and separating the pollution control and environmental protection is prone to breed local interests and sect oral interests. Therefore, we should focus on the regional integrity of legislation and system design so as to correct the current environmental legal system defects and deficiencies, we shall also roll out environmental legal system to resolve the problem of environmental legislation fragmentation caused by the administrative divisions and provide assurance for the method of legalization from the perspective of legal system. c. To improve the deterrence and binding forces of environmental law. Penalties and other administrative means of punishment are often applied in environmental law enforcement. In light of environmental enforcement, we should take full account of environmental pollution time, change the traditional static thinking mode and cancel the limits of the total amount of fines. The retrospective system shall also be applied and the fines should be received successively and start with the first day of environmental violations. The penalties will continue if the violations don't stop and the penalties can be accumulated in order to improve the illegal costs and avoid "one-time" administrative penalties. This could deter the "rational" enterprises and discourage the environmental violators. $d$. To establish the joint system between environmental law enforcement and administration of justice. At present, environmental law enforcement mainly depends on the administrative power of local government, however the "rational" government functions are subject to a variety of factors. So judicial relief is the last means of public power intervention. We should broaden the channels of environmental law enforcement and combine the environmental law enforcement with the judiciary from the legislative process to make up for the lack of enforcement. Judicial practice shows the court does not support the environmental protection department to enforce the application for there is no specific legal provision. Environmental enforcement cases are nonlitigation implementation and not included in the court evaluation mechanism. Its implementation earnings and in-place rate are low. The amendments should be made in the procedural law to define the intervention time and method of the court and other State compulsory organs so as to increase its support of environmental law enforcement. We can also consider increasing the system 
of real-time implementation. The environmental law enforcement departments can immediately apply for court enforcement and improve the environmental administrative reconsideration and the corresponding administrative litigation system. A. Roll out regional environment laws and regulations appropriate to the Yangtze River delta as soon as possible with Delta to adapt to the regional environmental laws and regulations. In order to highlight the concept of integration of regional environment, it is necessary to set up the institutional framework of regional cooperation, coordinate the regional inter-governmental competition pattern from the legislative point of view, clarify the power and obligation of the local governments and avoid the mutual prevarication so as to promote the legalization of Regional Environmental Governance in the Yangtze River delta. On the one hand, we can establish an organ for the coordination and leadership of environmental law enforcement coordination and leadership in the Yangtze River Delta. It is proposed that the Deputy Leader or State Councilor of the State Council lead the panel or the committee, take charge of planning, leadership and management of environmental governance in the region and eliminating the adverse effects of administrative barriers on environmental governance, thus providing assurance for environment governance for the legal point of view. On this basis, we can also establish a specific office under its leadership -the Yangtze River Delta Regional Environmental Management Bureau, which could be granted with the power and duty of handling and preventing environmental pollution. The office should be specifically responsible for management and coordination of regional environmental issues, improving Regional environmental coordination and management mechanism. It should also change divisive management pattern of different administrative areas and constrain the momentum of developing only the economy by local government. On the other hand, we shall improve the local power restrictions and management procedures from the perspective of legal system. The existing environmental legal system is more substantive than procedural, so the legal system cannot be implemented. Therefore, legal procedures for the specific implementation process must be provided. In the formulation of regional environmental management laws and regulations, we have to define the cooperation system and environmental management authority of the local government from the perspective of administrative system and procedural point of view. Division of labor should also be clarified on the water environment, the atmosphere, solid waste disposal and other issues. We shall focus on procedures legislation to ensure that laws and regulations are operational and avoid the local government's buck and prevarication.

Secondly, we shall build the regional environmental cooperation mechanism for the Yangtze River Delta region. .A. To build regional environmental coordination mechanism. At present, the major form coordinating pollution control in the Yangtze River Delta is joint meetings, which mainly coordinate by environmental cooperation agreements. But, this form has its limit and uncertainty. With the implementation of the rule of law, we should follow the guidance of full-time regional environmental governance institutions. Referring to the California South Coast Air Quality Management District Management Committee (SCAQMD), we can establish the Yangtze River Delta Regional Environmental Management Committee and grant its regional environmental management planning and specific implement power. The responsibilities of the administrative organ shall include the establishment of regional environmental governance planning, supervision, inspection, testing of regional environment as well as administrative examination and approval, recommendations, information disposal of environment entry. The organ shall have the power to carry out administrative coercion and punishment on regional environmental issues. The members of the institution shall include the provinces (municipalities) in the Yangtze River Delta region which could conduct democratic consultation on the same platform to meet the rights of different interest groups. In addition, we should also establish cross-border emergency linkage alliance for environmental pollution incident and develop work programs and specific response measures. B. To build a sound institutionalized governance mechanism. Cooperation between local governments in the region is the interest game among "rational persons". If we want 
to avoid the waste of regional environmental resources, we must find a breakthrough from the legal system design. The regional management leading group shall be led by the State Council, and the post of the Director of the Regional Environmental Law Enforcement and Coordination Administration of the Yangtze River Delta shall also be appointed by the Central Committee and the director of the environmental protection bereau of provinces and municipalities shall be remembers. The resolution shall be determined in the form of voting, monitored and implemented by the regional administration bereau. Besides, we shall enrich cooperation and supervision means, establish an integrated regulatory governance mechanism and implement joint monitoring of regional members, joint law enforcement, information sharing and ecological compensation thus strengthening regional environmental law enforcement. C. To build a multi-level environmental supervision and management mechanism. It is necessary to establish and improve the regional environmental monitoring network to gain information timely, identify problems and clear responsibility of the parties. We shall promote regional joint law enforcement. Members of the polluted region shall work and respond together. And we shall also establish emergency response and emergency response linkage mechanism to effectively deal with cross-border emergencies. We also need to set up information communication platform to promote information sharing among regional members, thus, effectively preventing the occurrence of pollution incidents. It is also necessary to establish regional ecological compensation mechanism and determine the mode of operation for regional ecological compensation in line with the principle of "who protect, who benefit", "who pollution, who compensate ".

Thirdly, we shall build an administrative system that protects the effect of environment law enforcement. A. To clear the authority of the department. The construction of the rule of law government requires that the administrative system must comply with the law. The government must act in accordance with the law so as to solve fundamentally the "unified management and classification, sub-sector management combined with the" environmental administrative system, clear departmental relations and put an end to overlapping functions so as to promote inter-ministerial collaboration in a legal form. We can refer to the experience of the United States and regard the environmental protection department as the competent department and the other for the collaboration sector. Then, we could promote the joint trial system on environmental protection and provide clear responsibilities as the basis for sectorial cooperation as well as policy and legal basis. B. To match real right with the fiscal rights. In line with the trend of streamlining power and administration, as for the local fiscal budget austerity caused by fiscal decentralization, the unmatched of the real right and the financial right as well as the fact of difficulty in providing sufficient environmental public goods, it is necessary to cultivate high-quality law enforcement personnel and improve their ability to perform law enforcement as well as import advanced technology and equipment and increase the environmental budget on environmental protection. By increasing financial transfer payments of the higher level of government and establishing the environmental-financial coordination mechanism, we could solve the problem of insufficient supply of real financial funds. And at the same time, we can try to put environmental administrative penalties into the environment protect budget through reasonable financial means of payment to ensure the financial support of environmental law enforcement. C. To straighten out the environmental law enforcement leadership system. Local environmental protection authority lack law enforcement, which to a large extent could be blamed by the dual leadership for local government, vulnerability of intervention in law enforcement by local party and restriction on exercising the law enforcement. In view of this, we can refer to the administrative system of the United States. In the system, the environmental law enforcement functions belong to the environmental protection department which is given the priority and right for environmental governance while recognizing other departments have environmental protection functions in order to avoid the uncertainty of conflict of interests and management relationship. To solve the dual leadership system, we can try the vertical leadership model of sub-provincial environmental 
protection agencies, reform the affiliation of environmental protection departments at all levels so as to ensure that law enforcement is not subject to administrative constraints. D. To improve the official performance evaluation and accountability system. Local leaders play a vital role in environmental protection. Legal policy, after all, rely on people to implement, so environmental protection is the real responsibility of local leaders. To improve the regional environmental law enforcement, we must improve the environmental awareness of local leaders. As the performance evaluation indicators have a strong guiding role for local leaders, therefore, performance evaluation must emphasize environmental objectives. Environmental protection and regional sustainable development indicators have to be regarded as important content of performance evaluation of the local leadership and the weight of environmental performance should be increased in the administrative performance. At the same time, we can raise environmental threshold of environment access in the Yangtze River Delta to encourage the development of environmentally friendly industries. We should focus on cultivating high-end modern financial services, cultural and creative industries, develop scientific research and development headquarters and eliminate high pollution and high energy consumption industry so as to achieve the goal of regional industrial transformation and upgrading and increasing industrial value-added. By doing that, we could also avoid environmental pollution caused by competition for manufacturing tax sources. We could use financial means to adjust access threshold for the local leader's lower access threshold in the competition for tax revenue and GDP. At the same time, improve the accountability system for local leaders. Those should be held accountable who cause serious pollution incident or regional major environment pollution incident due to laziness or neglect of duty. In addition, we shall also apply the departure tracking system. Those who cause environmental pollution or impact in office shall bear the responsibility.

Fourthly, we shall build a supervision mechanism of public participation. For the Yangtze River Delta regional environment Problem, we can strengthen external supervision, make the people living in the region participate in governance and supervise of government's governance. A. To assure people in the region of participating in the legislative process. Environmental legislation should abandon the departmental interests, elitist legislation and other ideas. Because legislation is a systematic social work which involves people's livelihood. The law must have a realistic basis and the basis of public opinion. It can neither lag nor ahead and need to reflect the people's will. "The role and task of the law is to recognize, identify, realize and protect the interests, or to hinder and waste at the minimal level to meet the conflicting interests." said Pound. Therefore, the operation of environmental laws and regulations should be based on the public and the legislation must consider its people's public opinion as well as gains and losses in order to develop laws that are in line with social needs and popular with people. If the majority of the people are absent in the legislative process and they cannot make their voices concerning their interests heard, then the people are deprived of the right to speak. Laws and regulations the legislative developed often have deviations and won't be echoed in legislation. B. To encourage the establishment of environmental citizens litigation system. The environmental citizen litigation system is a kind of public supervision system backed by judicial supervision. The system originated in the United States Environmental Law. US environmental experience shows that the system can effectively monitor the environmental performance of the government to make up for the lack of supervision of environmental authorities. Environmental public litigation allows citizens to better participate in environmental protection work and share the environmental responsibility undertaken by the government alone. The plaintiff qualification of the environmental protection departments in the environmental civil proceedings has been recognized by the Supreme People's Court, but the public and environmental organizations' plaintiff qualification in environmental public interest litigation has not yet been recognized. The plaintiff qualification should be given to the public and environmental protection organizations as soon as possible to promote the legalization of environmental protection. 


\section{REFERENCE}

[1] Jiaxing city bureau of statistics. 2015 Long triangle region economy development situation analysis.http://www.jiaxing.gov.cn/stjj/tjxx_6433/tjfx_6436/201 604/t20160401_584644.html

[2] Tens of thousands of residents have been cut off from the waters of jiaxing[N].http://finance.sina.com.cn 2005-7-5.China economic times

[3] 2007 taihu blue algae pollution incident. http://baike.so.com/doc/9263214-9596865.html

[4] Jiangsu Zhenjiang water pollution incident. http://baike.so.com/doc/6067797-6280864.htm

[5] Shanghai songjiang pig incident. http://baike.so.com/doc/5363433-5599004.html

[6] Fu piyi, dai jinsong, jiang xiao. The three difficulties of environmental protection in border area pollution disputes $[\mathrm{N}]$. Economic reference.

[7] 2007-12-13.http://jjckb.xinhuanet.com/gnyw/200712/13/content_77596.html

[8] The climate characteristics and changes of Shanghai fog and ting days $[\mathrm{J}]$. highland climate 2008, (6)

[9] Cheng zhen, Chen changhong. Effects of a cross-boundary pollution crossing in the Yangtze River delta region [J]. Journal of environmental science 2011, (4)

[10] Huang wenfang et al. Urban environment: governance and law enforcement $[\mathrm{M}]$. Fudan university press 2010 edition

[11] Lu cheng. Administrative cooperation on water pollution regulation [D]. University of suzhou doctoral dissertation, 20103-1

[12] Wang canfa. Research on the management of water environment management in the region [J]. Modern law. 2005, (5)

[13] A study on the countermeasure of the overall force of the long delta port group [J]. Jiangnan BBS 2015, (2)

[14] Huang mingjian. Theory of environmental law system [M]. 